\title{
Article
}

\section{Open Source Completely 3-D Printable Centrifuge}

\author{
Salil S. Sule ${ }^{1}$, Aliaksei L. Petsiuk ${ }^{2}$ and Joshua M. Pearce $2,3,4, *$ (D) \\ 1 Department of Mechanical Engineering-Engineering Mechanics, Michigan Technological University, \\ Houghton, MI 49931, USA; ssule@mtu.edu \\ 2 Department of Electrical \& Computer Engineering, Michigan Technological University, Houghton, \\ MI 49931, USA; apetsiuk@mtu.edu \\ 3 Department of Material Science \& Engineering, Michigan Technological University, Houghton, \\ MI 49931, USA \\ 4 Department of Electronics and Nanoengineering, School of Electrical Engineering, Aalto University, \\ FI-00076 Espoo, Finland \\ * Correspondence: pearce@mtu.edu or joshua.pearce@aalto.fi; Tel.: +01-906-487-1466
}

Received: 16 April 2019; Accepted: 15 May 2019; Published: 18 May 2019

\begin{abstract}
Centrifuges are commonly required devices in medical diagnostics facilities as well as scientific laboratories. Although there are commercial and open source centrifuges, the costs of the former and the required electricity to operate the latter limit accessibility in resource-constrained settings. There is a need for low-cost, human-powered, verified, and reliable lab-scale centrifuges. This study provides the designs for a low-cost 100\% 3-D printed centrifuge, which can be fabricated on any low-cost RepRap-class (self-replicating rapid prototyper) fused filament fabrication (FFF)- or fused particle fabrication (FPF)-based 3-D printer. In addition, validation procedures are provided using a web camera and free and open source software. This paper provides the complete open source plans, including instructions for the fabrication and operation of a hand-powered centrifuge. This study successfully tested and validated the instrument, which can be operated anywhere in the world with no electricity inputs, obtaining a radial velocity of over $1750 \mathrm{rpm}$ and over $50 \mathrm{~N}$ of relative centrifugal force. Using commercial filament, the instrument costs about U.S. \$25, which is less than half of all commercially available systems. However, the costs can be dropped further using recycled plastics on open source systems for over $99 \%$ savings. The results are discussed in the context of resource-constrained medical and scientific facilities.
\end{abstract}

Keywords: 3-D printing; additive manufacturing; biomedical equipment; biomedical engineering; centrifuge; design; distributed manufacturing; laboratory equipment; open hardware; open source; open source hardware; medical equipment; medical instrumentation; scientific instrumentation

\section{Introduction}

Adopting an open-source model of technological development enables equipment designers to quickly build upon one another's work [1-3]. This democratization of design assists many individuals in effectively working together by making a range of contributions over time using open source tools [4-6]. Some of the most effective tools for encouraging widespread open hardware designs are themselves means of digital distributed manufacturing $[7,8]$. For example, the open source nature of the self-replicating rapid prototyper (RepRap) 3-D printer [9-11] has radically increased the accessibility of additive manufacturing (AM) while eviscerating the costs of rapid prototyping and product fabrication [12-15]. RepRaps and derivative commercial variants have obtained mechanical 3-D printed part strengths [16] and qualities of interest to the scientific community [17]. Many open source digitally fabricated devices are now widely used by the scientific community [18-20]. For example, 3-D printed parts are used in chemical mixing [2,20-24], optical and mechanical testing [24-26], water quality 
testing [27-30], and syringe pumping [31-34] (which can be in turn used for more complicated systems such as fabricating microfluidics and metafluidics [35-37] or slot die deposition [38]). In addition to offering scientists the ability to customize their equipment and fully control their function, open source 3 -D printable tools are much less expensive than equivalent or inferior commercial systems $[18,39,40]$. In general, these economic savings are greater for a high percentage of the components able to be 3-D printed [41]. A high return on investment (ROI) is realized for distributed manufacturing with commercial polymer 3-D printing filament based on downloaded substitution values [42,43]. In order to continue to "stand on the shoulders of giants" in open hardware [44], this paper describes the design of an open source completely 3-D printable centrifuge.

A centrifuge is a machine that holds rapidly rotating containers while applying centrifugal force to the fluids inside the containers to separate them based on different densities. Centrifuges are commonly required devices in medical diagnostics facilities because they are used for determining the concentration of pathogens and parasites in biological fluids, DNA preparation, and the extraction of plasma from the whole blood needed for immunoassays or hematocrit analysis. There are many commercial laboratory centrifuges and a number of open source variants, including the open analytical ultracentrifugation (AUC) [45], the laser cut OpenFuge [46], the Polyfuge [47], several variations of minicentrifuges [48-50], and one that uses a Dremel and 3-D printed chuck [51]. These open hardware tools do provide for those without access to more expensive proprietary tools [52], but they all depend on access to electricity. Unfortunately, an estimated 1.1 billion people (e.g., $14 \%$ of the global population) do not have access to electricity [53]. In addition, even many of those that do have access to electricity have unreliable power. For example, in Nigeria, power outages over extended times have forced a shift to expensive and polluting captive power generation in the majority of businesses [54]. To overcome this challenge of reliable electric power, several open source hand-powered centrifuges have been developed, including the paperfuge [55], a salad spinner centrifuge [56], and an eggbeater centrifuge [57]. All of these are functional, but they lack either large volume capabilities [55] or reliability. To overcome this, several companies have commercialized relatively robust hand-crank centrifuges, which cost U.S. $\$ 60-100[58,59]$. These costs can still be prohibitive, and as centrifugation is the first key step in most diagnostic assays [60], there is a need for a low-cost, portable, human-powered centrifuge that can be used by scientists and medical personnel, especially for diagnostics in resource-limited environments [60-63].

This study provides the designs for a low-cost 100\% 3-D printed centrifuge apparatus, which can be fabricated on any low-cost RepRap-class fused filament fabrication (FFF)- or fused particle fabrication (FPF)-based 3-D printer. In addition, a validation procedure for quantifying the rotational speed is provided, which makes use of a smart phone or web camera. The design was fabricated and tested, and the results are discussed in the context of resource-constrained medical and scientific facilities.

\section{Materials and Methods}

\subsection{Design}

The design goal for this apparatus was to provide 1200 rotations per minute (rpm), with a handle rotational speed of the operator $\left(N_{1}\right)$ of $120 \mathrm{rpm}$ (i.e., 2 rotations in $\left.1 \mathrm{~s}\right)$. This centrifuge apparatus uses one set of spur gears and one set of bevel gears to achieve the desired gear ratio. Figure 1 shows the design of the gearing system. 


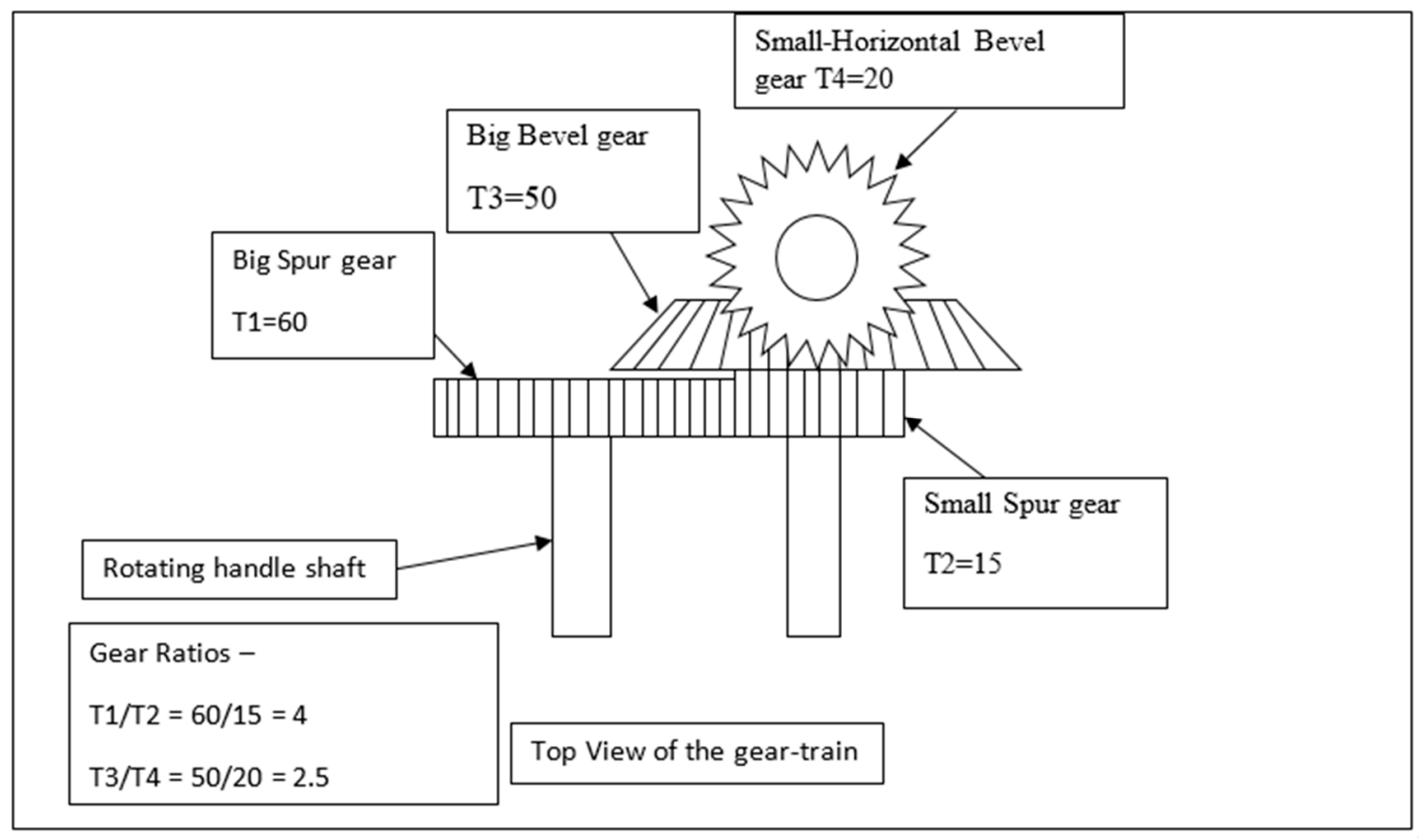

Figure 1. Schematic of gear design.

\subsubsection{Gear Designing and Final Drive Calculations}

Considering the rotational speed of the handle by the operator, $N_{1}$ to be $120 \mathrm{rpm}$, the rotational speed for the 2nd spur gear, $N_{2}$, is equal to $480 \mathrm{rpm}$ :

$$
\mathrm{N}_{2}=\mathrm{N}_{1} \mathrm{~T}_{1} / \mathrm{T}_{2}
$$

with the following teeth for the four gears:

- $\quad$ Teeth on 1st spur gear: $T_{1}=60$;

- $\quad$ Teeth on 2nd spur gear: $T_{2}=15$;

- Teeth on 1 st bevel gear: $T_{3}=50$;

- $\quad$ Teeth on 2 nd bevel gear: $T_{4}=20$.

Thus, $N_{2}$ is $480 \mathrm{rpm}$, and as the 2nd spur gear and 1st bevel gear are coupled together,

$$
\mathrm{N}_{2}=\mathrm{N}_{3}
$$

Thus,

$$
\mathrm{N}_{4}=\mathrm{N}_{3} \mathrm{~T}_{3} / \mathrm{T}_{4}=\mathrm{N}_{2} \mathrm{~T}_{3} / \mathrm{T}_{4}
$$

Thus, $N_{4}$ is $1200 \mathrm{rpm}$. Similarly, for an $N_{1}$ of $150 \mathrm{rpm}$ (i.e., 2.5 rotations of the handle per second), the final rotor speed is $1500 \mathrm{rpm}$.

Thus, for this apparatus, the number of test tube rotations $\left(r_{t}\right)$ is given by

$$
\mathrm{r}_{\mathrm{t}}=\mathrm{Cr}_{\mathrm{h}}
$$

where the hand rotations per minute $\left(r_{h}\right)$ can be measured, and $C$ is a constant of 10 . With these parameters, it is also possible to calculate the relative centrifugal force (RCF), which is the amount of acceleration that is exerted on the sample in the apparatus. The RCF is dependent on the speed of the 
rotor and the distance of the matter in the test tubes from the center of the rotation. When the unit of rotation $\left(N_{4}\right)$ is in rpm, the RCF is given by

$$
\mathrm{RCF}=1.118 \times 10^{-6} \times \mathrm{R}[\mathrm{mm}] \times \mathrm{N}_{4}^{2}[\mathrm{rpm}]
$$

where $R$ is the radius of the rotor to the center of the test tubes used added to the test tube length (mm), and $N_{4}$ is given by Equation (3). In the example shown here, with the radius of the rotor (50 mm) test tubes used and the length of the test tubes $(100 \mathrm{~mm})$ providing a total of $150 \mathrm{~mm}$ and an $N_{4}$ of 1500 rpm, the RCF is 377 .

\subsubsection{Operation of Design}

1. Rotating the handle rotates the bigger spur gear, which starts the motion. The two spur gears in contact have equal modules. The module is the ratio of the reference diameter of the gear to the number of teeth on the gear. The bigger spur gear has 60 teeth and a module of 2 . Although a larger spur gear would yield a higher gear ratio, it would also increase the size of the casing and in turn the size of the whole apparatus. A spur gear with 60 teeth and a module of 1.5 modules was chosen, considering the need of the final required rotations of the rotor $\left(N_{4}\right)$. Meshed to the bigger spur gear is a smaller spur gear with an equal module. To mesh and rotate a set of any gears, it is necessary that both the gears should have the same profile and an equivalent module. This smaller spur gear is coupled to a larger bevel gear to eliminate the overhang and also another component required to hold the two together. The bigger bevel gear has 50 teeth and a module of 2. The bevel gear is used to transmit the motion in a perpendicular direction. A smaller bevel gear is then meshed with the large one to increase the rotations per minute of the test tubes.

2. High rotational speeds of 1200-2000 rpm are required to carry out typical medical tests. Thus, this gear train is designed in such a way that, with every two rotations per second, the rotor rotates at $1200 \mathrm{rpm}$. With every 2.5 rotations per second of the handle, the rotor rotates at $1500 \mathrm{rpm}$, and with 3 rotations per second, it can do $1800 \mathrm{rpm}$. The commercial equivalent products are capable of rotating at $1800 \mathrm{rpm}$, which is equal to the rotational capability of this 3-D printed centrifuge apparatus. The speeds can be easily increased if the number of teeth on either of the bevels or spurs or both bigger gears are increased and the source code in FreeCAD (computer-aided design 3-D modeling software, www.freecadweb.org) is made available for those that need this capability.

3. The dimensions of the handle are designed in such a way that it will not interfere with the rotation of the test tubes. The grip is designed to keep in mind the ergonomics of the human hand and its motion while rotating the handle. Enough grip is provided on the grip bar, which freely rotates around the centerpiece of the handle. The horizontal motion of grip is constrained by implementing a ball-socket joint at the end of the handle.

4. Test tubes are placed in the test rings, which are specifically designed for standard test tubes. However, there is a wide variety of test tubes that are available on the market. All of the part files in FreeCAD are made available and open source so that others can adapt the tube holders to meet other sizes of test tubes. The test rings that hold the test tubes are locked in the rotor by using rotor snaps. These snaps can easily withstand the high centrifugal forces acting on them, as they are tightly fitted in the rotor itself. The rotor diameter is $120 \mathrm{~mm}$, which is enough to generate high centrifugal force, following Equation (4).

\subsubsection{Bill of Materials}

The bill of materials (BOM) is made up of all 3-D printed components, which are summarized in Table 1. 
Table 1. Bill of materials for the 3-D printed open source centrifuge.

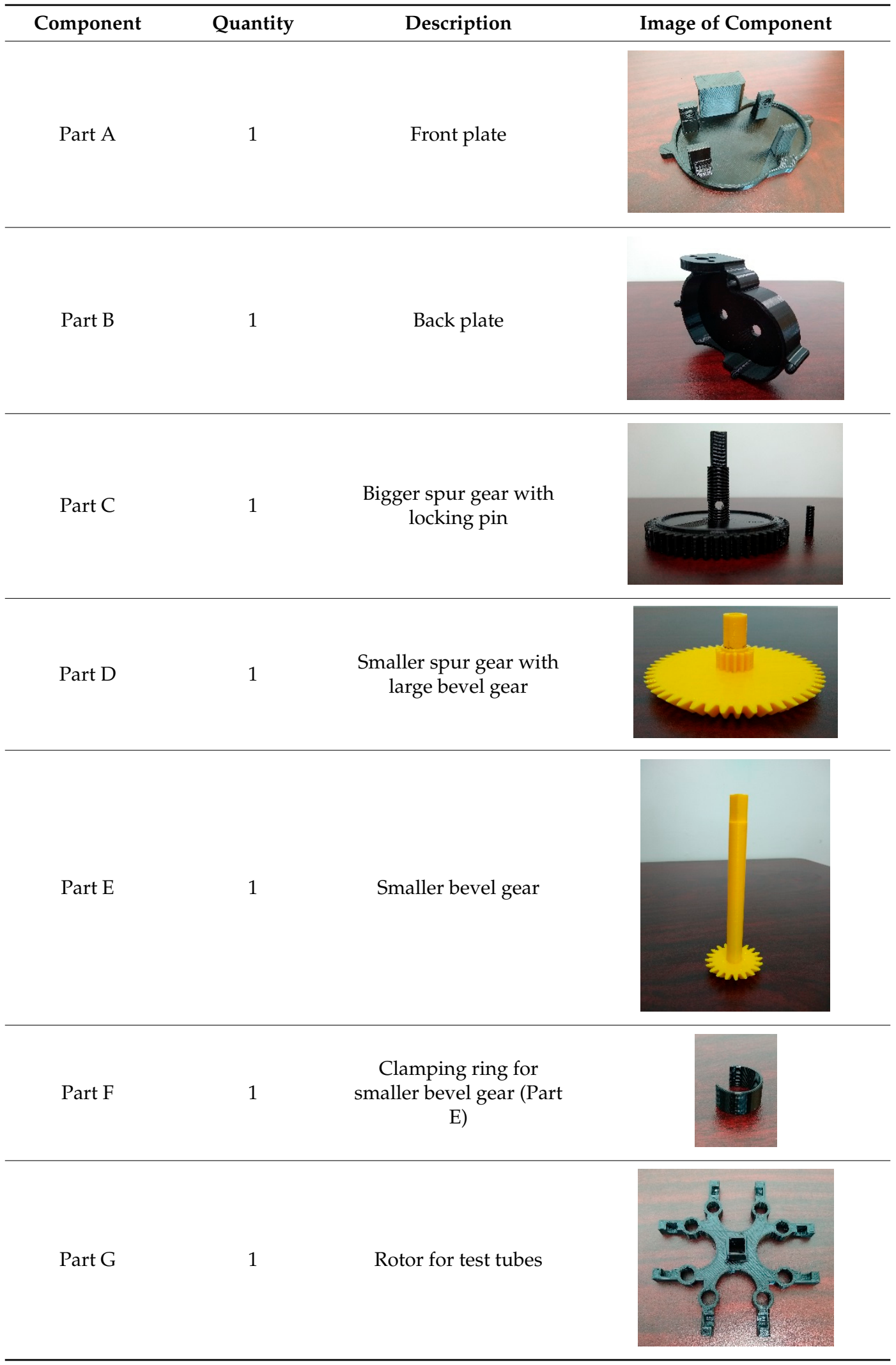


Table 1. Cont.

\begin{tabular}{|c|c|c|c|}
\hline Component & Quantity & Description & Image of Component \\
\hline Part $\mathrm{H}$ & 1 & Clamping for Part D & \\
\hline Part I & 4 & Rings for test tube & \\
\hline Part J & 8 & Snaps for rotor & \\
\hline Part K & 2 & Bolts for clamping body & \\
\hline Part L & 2 & Base clips for the bolts & \\
\hline Part M & 1 & $\begin{array}{l}\text { Smaller bevel gear } \\
\text { holder }\end{array}$ & \\
\hline
\end{tabular}


Table 1. Cont.

\begin{tabular}{|c|c|c|c|}
\hline Component & Quantity & Description & Image of Component \\
\hline Part N & 1 & Handle & \\
\hline Part $\mathrm{O}$ & 1 & Grip for handle & \\
\hline Part P & 1 & Locking clip for handle & \\
\hline
\end{tabular}

\subsection{Fabrication}

The components shown in Table 1 are available on the Open Science Framework [64] and are released under a GNU General Public License (GPL) 3.0 [65]. Parts K and L are borrowed from a creative commons-licensed C-clamp design [66]. All of the parts were 3-D printed with glycol-modified polyethylene terephthalate (PETG) IC3D filament of diameter $2.85 \mathrm{~mm}$ on a Lulzbot TAZ 6 (Aleph Objects, Loveland CO). The objects were sliced with Cura Lulzbot edition v.3.6.3 [67] using the standard settings summarized in Table 2.

Table 2. Slicer settings for each 3-D printed part.

\begin{tabular}{ccc}
\hline Part Name & Predefined Settings (Layer Height) & Infill (\%) \\
\hline A & High speed $(0.38 \mathrm{~mm})$ & 40 \\
B & High speed $(0.38 \mathrm{~mm})$ & 40 \\
C & Standard $(0.28 \mathrm{~mm})$ & 65 \\
D & Standard $(0.28 \mathrm{~mm})$ & 60 \\
E & Standard $(0.28 \mathrm{~mm})$ & 60 \\
F & High speed $(0.38 \mathrm{~mm})$ & 90 \\
G & High speed $(0.38 \mathrm{~mm})$ & 40 \\
H & High speed $(0.38 \mathrm{~mm})$ & 40 \\
I & Standard $(0.28 \mathrm{~mm})$ & 50 \\
J & Standard $(0.28 \mathrm{~mm})$ & 60 \\
K & Standard $(0.28 \mathrm{~mm})$ & 50 \\
L & High speed $(0.38 \mathrm{~mm})$ & 50 \\
M & High speed $(0.38 \mathrm{~mm})$ & 65 \\
N & High speed $(0.38 \mathrm{~mm})$ & 75 \\
O & High speed $(0.38 \mathrm{~mm})$ & 45 \\
P & High speed $(0.38 \mathrm{~mm})$ & 40 \\
\hline
\end{tabular}




\subsection{Assembly}

All of the parts of the centrifuge apparatus are shown in Table 1, from Part A through Part O. The assembly of the open source centrifuge can be accomplished after the printed parts are prepared as follows. Part $C$ is the big spur gear, whose end part (square-shaped) needs to be scraped with a knife or any sharp object before starting the assembly. Make sure to scrape a little material from the four edges on the square-shaped end of Part $C$ to ensure a tight fit between Part $C$ and the handle (Part $\mathrm{N})$. This is an important step, as a tight fit will make rotating the handle easy and effective. All of the holes on Part A and Part B need to be scraped a little to ensure smooth rotations of the respective gears. This problem is created due to non-uniform printing by the FFF printer. The four sockets on Part A are to be scraped as well for perfect fitting of the ball joints of Part B. Carefully remove a small amount of material from all four sockets if the ball joints are not fitting inside the sockets. This operation may require some extra force. Part $\mathrm{A}$ and Part $\mathrm{B}$ are the two casings, which cover the gear train of the apparatus. Start assembling with Part B, as the gears are meshed inside this part (Figure 2).

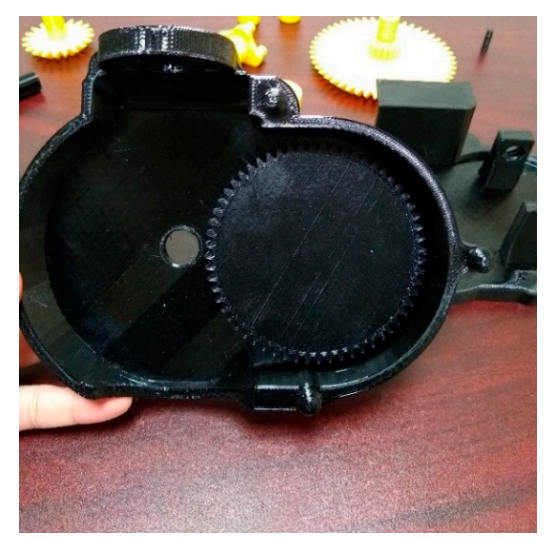

Figure 2. Assembling Parts B and C.

Part $B$ has two holes of equal diameter where the gears are placed in order to carry out correct meshing. The right-hand side of Part B has a smaller diameter casing than the left-hand side does. Place Part $C$, which is the bigger spur gear, through the hole on the right-hand side (the smaller casing side, as seen in Figure 2). Lock the spur gear from the backside with the small connecting pin, which is included in Part C. This will help to constrain the horizontal movement of the spur gear and will keep the shaft in place while rotating.

Now insert Part E through the bigger circle situated on the top of Part B and hold it at the top (Figure 3a). Then insert Part D, which is the part with coupled gears, through the hole on the left side of Part B (Figure 3b).

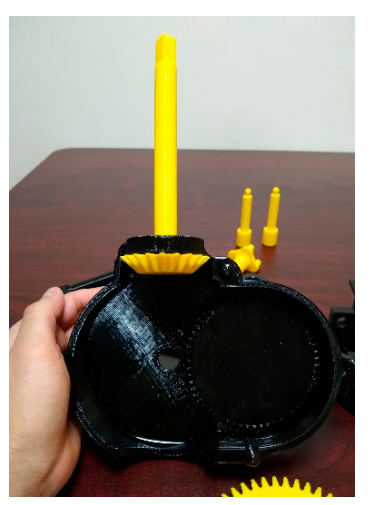

(a)

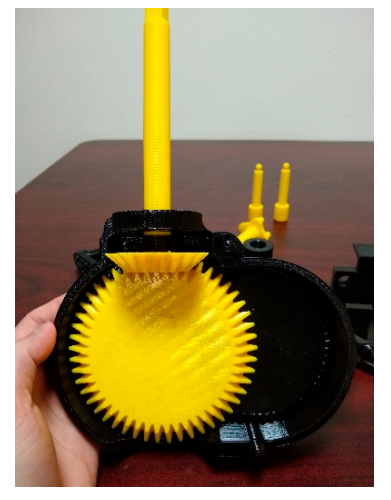

(b)

Figure 3. (a) Inserting Part E into Part B and (b) inserting Part D. 
Attach part $\mathrm{H}$ from the backside of Part B in Part E's hole, which will hold the couple gears in one place and stop them from swiveling abruptly while rotating (Figure 4a). Then place Part F, which is a small ring or clamp, to constrain the vertical motion of Part E (Figure 4b).

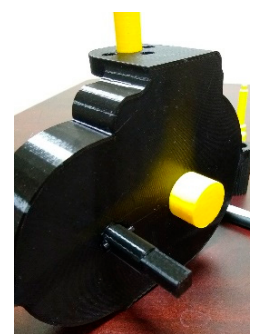

(a)

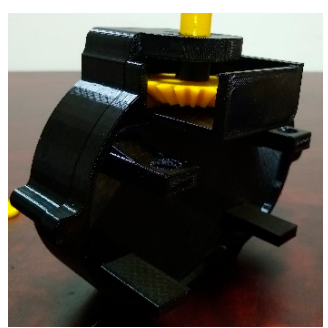

(b)

Figure 4. (a) Attaching Part $\mathrm{H}$ and (b) Part E.

Part A is the other half of the casing, which is used to cover the gear train and clamping. Part A and Part B are clamped to each other using four ball-socket joints. Insert Part M through Part E's square end and fix it to the casing through the three given holes (Figure 5a). This will help the small bevel gear align perfectly in a vertical direction during rotations. Part $\mathrm{K}$ and Part $\mathrm{L}$ are used to clamp the whole centrifuge body to any even surface. Join both parts after Part K is passed through Part A's internal threading. Join Part K and Part L using the ball-socket joint (Figure 5b).

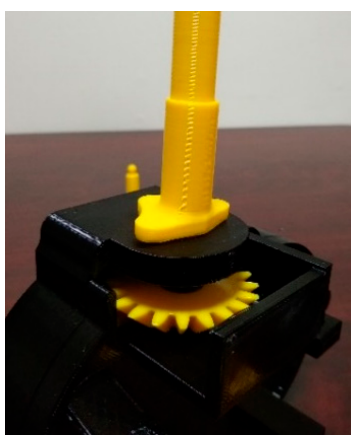

(a)

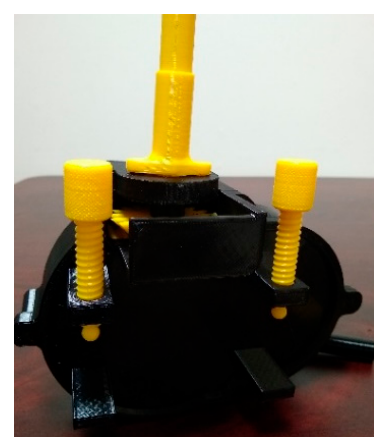

(b)

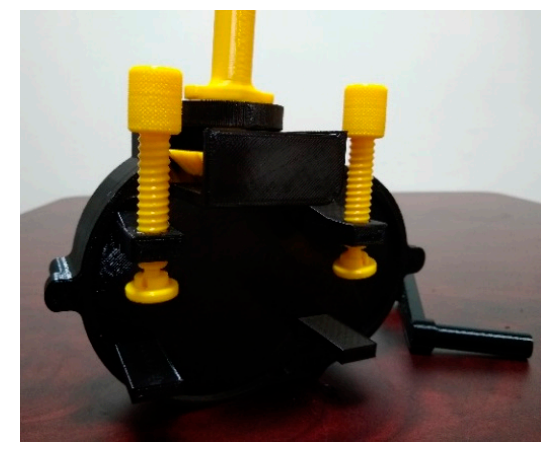

(c)

Figure 5. (a) Inserting part $\mathrm{M}$ and (b) assembling Parts $\mathrm{K}$ and (c) L.

Part N, Part O, and Part P are the components of the handle. Lock Part $\mathrm{N}$ in the square end of Part C (Figure 6a). Make sure to scrape some material with the help of a knife or any sharp object from Part C's square end to tightly fit Part C with Part N. If sufficient material is not scraped, then Part C will not fit with Part $\mathrm{N}$, and if it is scraped more, then the handle will fit loosely, which will create a snapping problem while rotating the handle. Part $\mathrm{O}$ is the grip (Figure $6 \mathrm{~b}$ ), which is used to rotate the handle. Fix Part $\mathrm{O}$ and Part $\mathrm{P}$ with the ball-socket joint to fix the grip (Figure 6c).

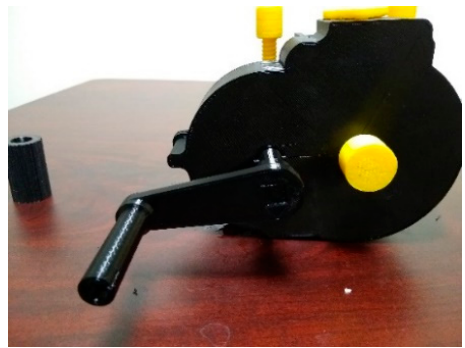

(a)

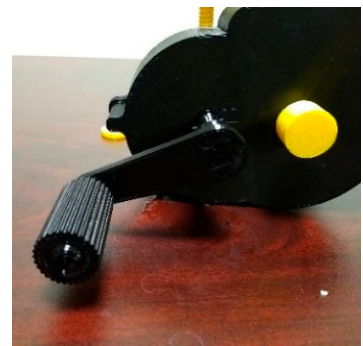

(b)

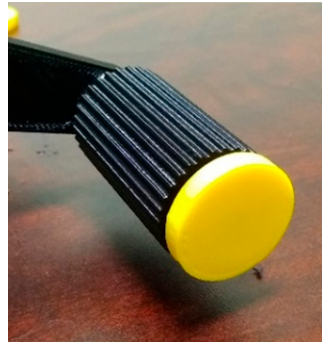

(c)

Figure 6. (a) Attaching handle N, and the (b) grip and (c) lock. 
Part G, Part I, and Part J are the parts of the rotor assembly (Figure 7). Part G is the rotor that will hold the rings (Part I) and the snaps (Part J). Place the rings in the rotor and clamp the rings by placing the snaps into the rotor. This will prevent the rings from falling during the motion due to high centrifugal force.

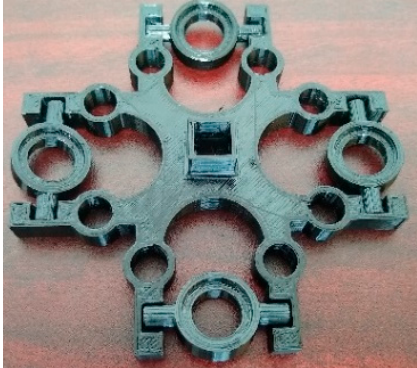

(a)

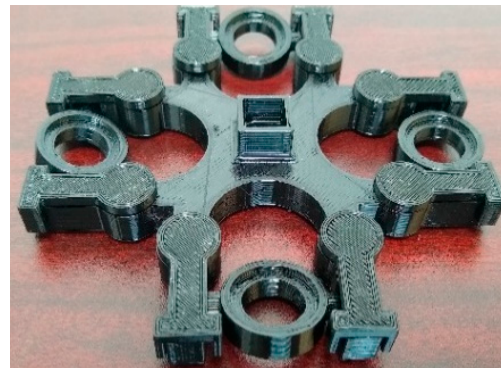

(b)

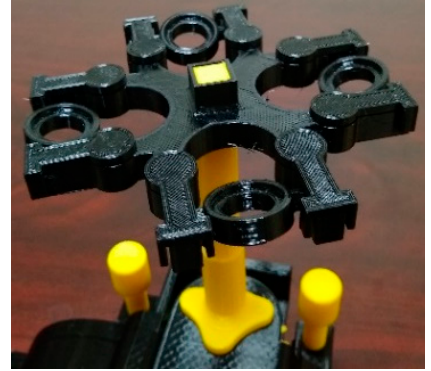

(c)

Figure 7. Assembling (a) Part G, (b) Part I, and (c) Part J.

\subsection{Operation}

After completing the assembly, clamp the centrifuge apparatus on one side of a table (preferably a rectangular table and not a circular one). Place the test tubes in the test tube rings carefully. It is extremely important to balance the weight of the test tubes equally. Leaving out test tubes or heavily loading one will cause vibrations and will make the whole apparatus unstable while in operation. If only 3 of the test tubes are used for sample testing, make sure to fill the fourth test tube with water or a liquid that is of similar density to that of the sample. This will ensure an equal distribution of weight. Crank the handle, which is equipped with a grip.

\subsection{Validation}

As the working part of the centrifuge rotates at a speed of up to $2000 \mathrm{rpm}$, it may be difficult to track its motion, since the majority of regular web cameras operate at a frequency of $25-30 \mathrm{~Hz}$. Thus, as the whole system represents a mechanical transmission with the fixed gear ratio, an indirect method was chosen to calculate the angular velocity of the tubes based on the speed of rotation of the centrifuge handle (Figure 8).

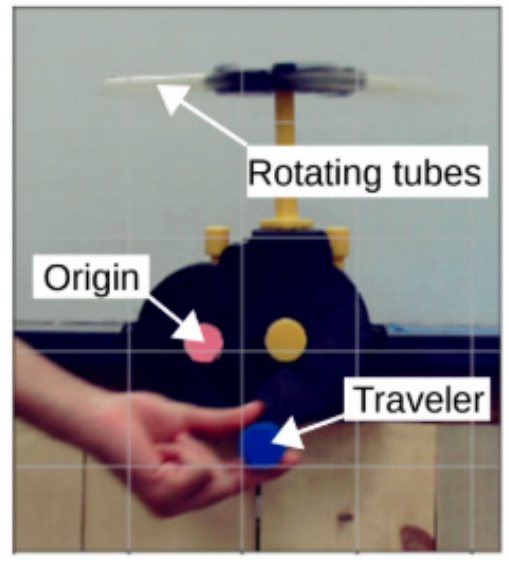

(a)

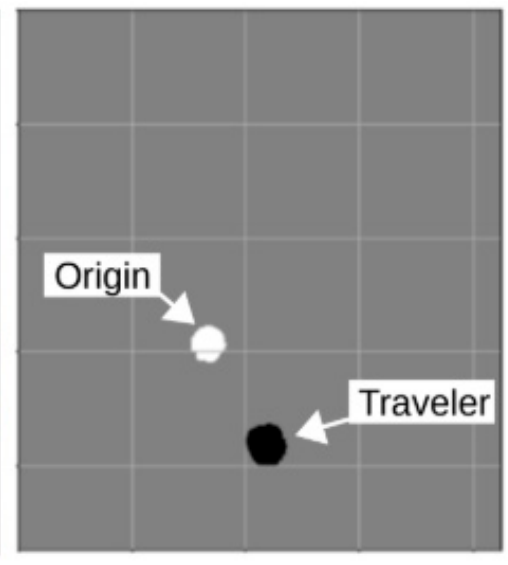

(b)

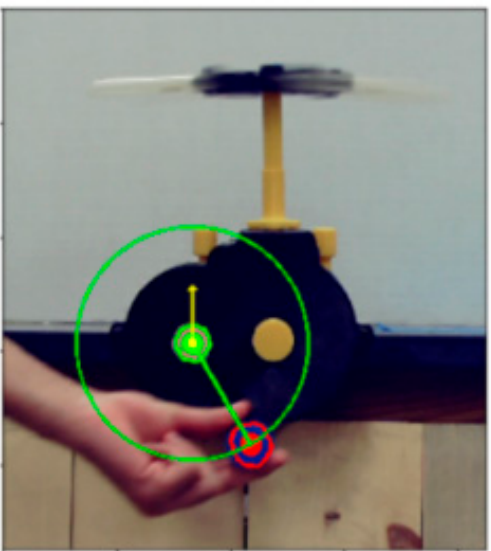

(c)

Figure 8. Image-based markers segmentation. (a) Cropped frame of the centrifuge with the visual markers; (b) masked image; (c) calculated handle orientation.

A Python-based software was developed to automatically measure the rotational speed of the centrifuge. The OpenCV library [68] was used for segmentation and tracking a visual marker located 
on the centrifuge handle, and the PyQt library [69] was used for creating an open source guided graphical user interface (GUI) application (Figure 9) [70].

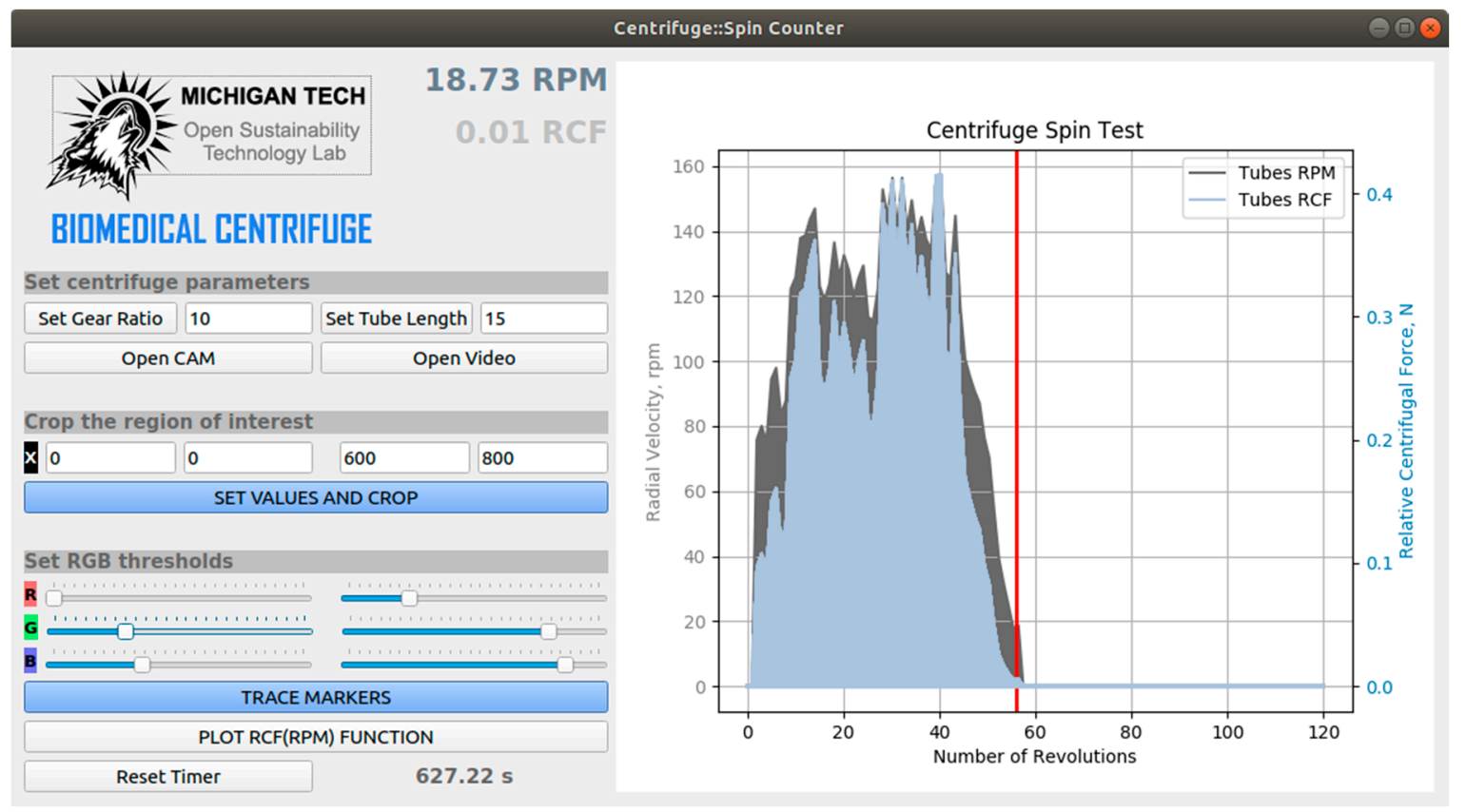

Figure 9. A screenshot of the open source biomedical centrifuge interface for camera-based rpm and relative centrifugal force calculations.

The developed application allows users to crop an arbitrary region of interest of the captured camera frame and set red, green and blue (RGB) thresholds for tracking the visual markers of any distinctive colors. It counts the number of centrifuge handle revolutions and calculates the angular velocity of the tubes. With the given information about the tube length, the program also computes its relative centrifugal force. In the case of normal manual rotation, the central marker will be periodically covered by the hand/arm of the user, so it is possible to set the $x$ and $y$ coordinates of the origin point in the program code.

The main computer vision algorithm is provided below. The rpm and RCF calculations are based on tracking the coordinates of the traveler marker located on the centrifuge handle. By applying the specified color thresholds and morphological operations of "opening" and "closing" to a cropped camera frame, the user can mask the marker as a single separated color region. To find the coordinates of its centroid, the method of moments is employed, which allows the centrifuge handle orientation relative to the center of rotation to be calculated. To do this, $R P M_{T}$, the rotational velocity of the tubes in rpm, is given by

$$
\mathrm{RPM}_{\mathrm{T}}=\mathrm{G} \cdot \frac{60}{\Delta \mathrm{t}}
$$

where $G$ is the gear ratio and $\Delta t$ is the time interval for a single revolution in seconds. The RCF is given by

$$
\mathrm{RCF}=1.118 \cdot 10^{-6} \cdot \mathrm{D} \cdot \mathrm{RPM}_{\mathrm{T}}^{2}
$$

where $D$ is the length of the test tube with the radius of the centrifuge rotor in $\mathrm{mm}$. A series of eight experiments for various rotational speeds for an $\mathrm{RCF}(\mathrm{rpm})$ plot were performed to compare the theory to experiments. Such a validation experiment is recommended for those building their own centrifuge before deployment. Depending on the critical nature of the application of the open source centrifuge, users may wish to record and run the validation for every experiment or simply keep track of the approximate number of rotations and rotations/minute of the handle to obtain an approximate $\mathrm{RCF} / \mathrm{rpm}$. 
As can be seen in Figure 9, the user can set the RGB thresholds and crop the region of interest in the video. Users can also set the tube length and gear ratio to calculate the rpm and RCF. The RCF and rotational velocity are plotted in real time. The pseudo-code is given as follows:

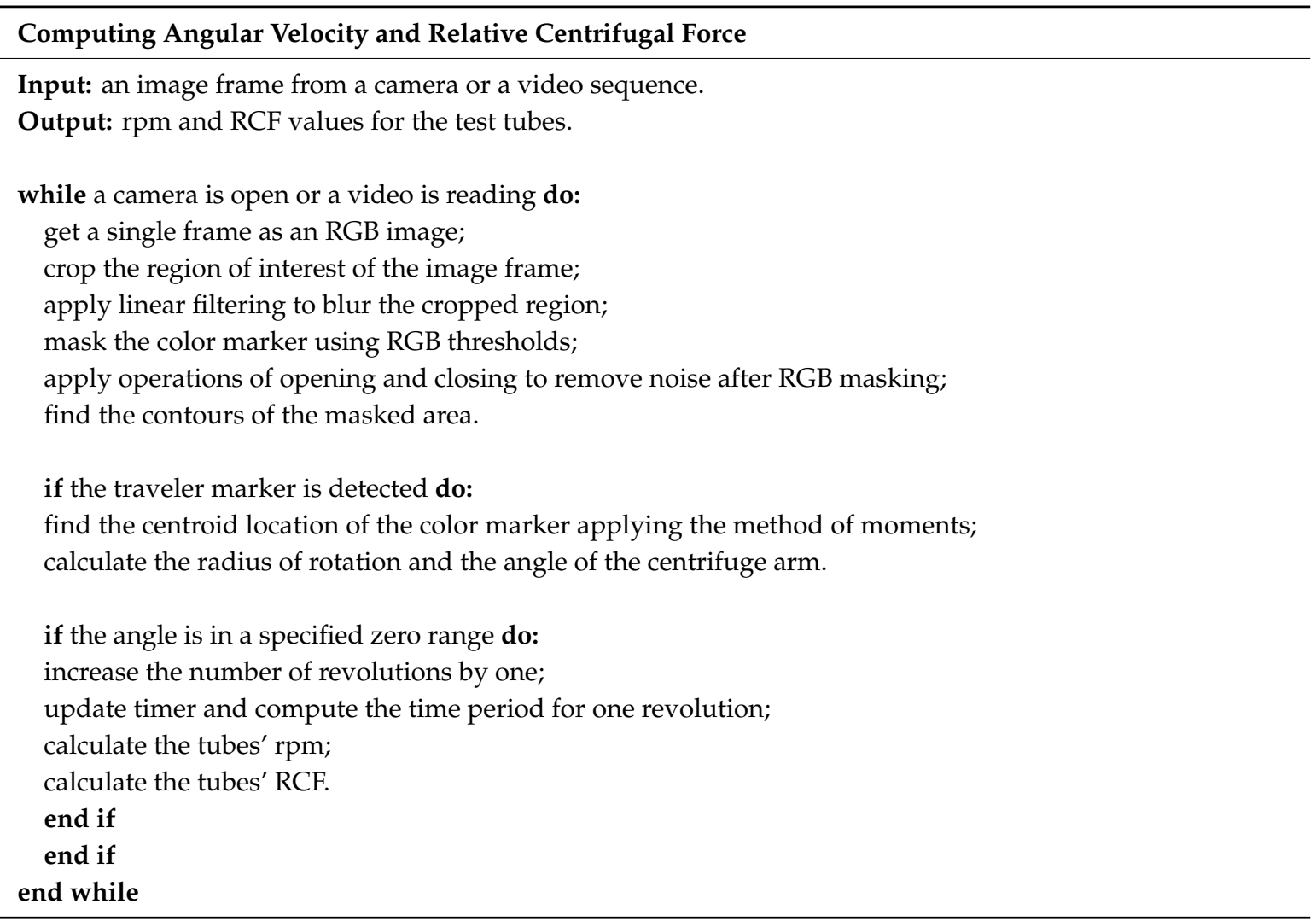

\subsection{Economic Analysis}

In order to determine the costs of the apparatus, the entire device was massed on a digital scale $+/-0.01 \mathrm{~kg}$. The total cost $\left(T_{c}\right)$ of the apparatus can be determined by

$$
\mathrm{Tc}=\mathrm{mCe}+\mathrm{mCp}
$$

where $m$ is the mass of all the 3-D printed parts (e.g., the whole apparatus); $C_{e}$ is the cost of the electricity per $\mathrm{kg}$ to print; and $C_{p}$ is the cost of plastic per $\mathrm{kg}$. The electricity to operate the Lulzbot Taz 6 is about $9.11 \mathrm{kWh}$ per $\mathrm{kg}$, as measured by a multimeter $+/-0.01 \mathrm{kWh}$. The average cost of commercial electricity in the U.S. is $\$ 0.1029 / \mathrm{kWh}$ [71]. This value was used, assuming that the device was fabricated at a university or government laboratory, which would be considered a midrange value between those fabricating it using residential electricity rates (higher) and distributed solar photovoltaic electricity (lower). The cost of an IC3D filament from Lulzbot was U.S. \$45/kg [72].

\section{Results}

All of the parts of the open source centrifuge can be printed on a standard RepRap-class FFF-based 3-D printer. Here, all of the parts were printed on a Lulzbot Taz 6 using standard print settings in PETG. Part A and Part B are the longest prints, and take more than $8 \mathrm{~h}$ to complete each. All of the gears are printed with more than $60 \%$ fill, and thus they have printing times of more than three hours. The total printing time for all of the parts is about $35 \mathrm{~h}$. The printing time can be reduced if the "high speed" (0.28 mm $z$ height) predefined setting is used with a reduction in the infill percentage up to a certain level. In addition, a nozzle with a larger orifice would also speed up printing. 
The open source centrifuge takes about $30 \mathrm{~min}$ to assemble after printing all of the parts if all the instructions in Section 2.3 are carefully followed. The open source centrifuge is shown fully assembled in a pre-spin state clamped to a desk in Figure 10. The complete system with filled test tubes is shown during rotation in Figure 11a, and a screen capture of a centrifuge cam used for the GUI is shown in Figure 11b. Note the blue tape on the handle end to enable easy computer vision analysis. The same functionality can be obtained using a different colored 3-D print for Part P, coloring it with a marker, or using a sticker. To see the device in operation, see Supplementary Materials, Video S1: MOST_CENTRIFUGE_VIDEO.avi.

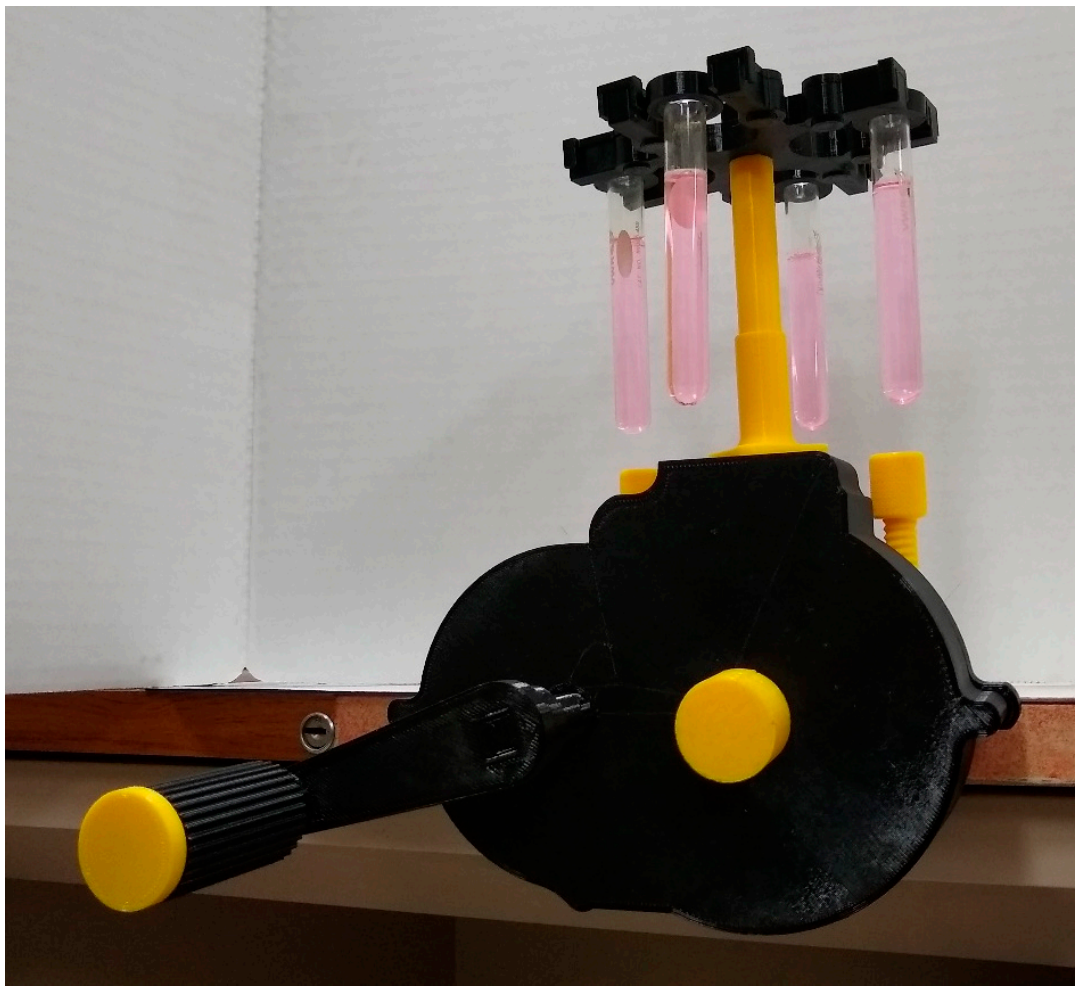

Figure 10. Fully assembled open source centrifuge in a pre-spin state.

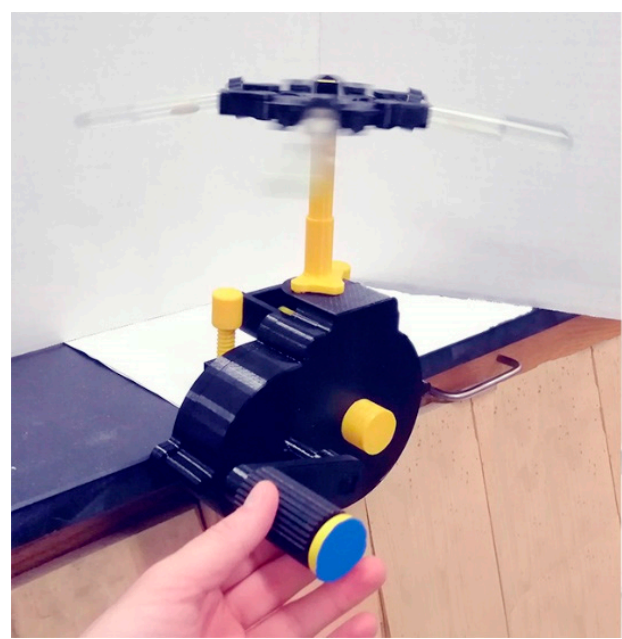

(a)

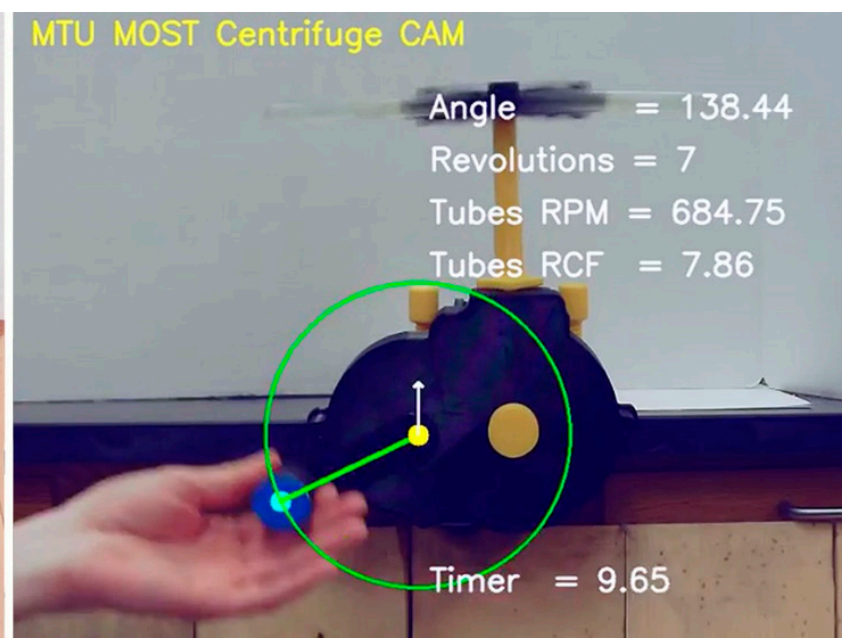

(b)

Figure 11. (a) Complete system with filled test tubes during rotation and (b) a screen capture of a centrifuge cam used for the graphical user interface (GUI). Tracking of the handle marker, time, angle, number of revolutions, rpm, and RCF are all shown in real time. 
During validation experiments with filled test tubes, the RCF(rpm) function was obtained for a wide range of rotational velocities and compared to theoretical Equation (5) for the test tubes with a length of $100 \mathrm{~mm}$ and a total radius of rotation $D=150 \mathrm{~mm}$ (Figure 12). The goal of the validation was to confirm that there was no time delay in the computer program between calculating the rotational velocity and the relative centrifugal force. As can be seen in Figure 12, the apparatus performed as expected from a start at stationary to over $1750 \mathrm{rpm}$. This verified the real-time plot (Figure 9), which displayed a proper $\mathrm{RCF} / \mathrm{rpm}$ ratio over time and over the full range of rotational velocities. In locations without access to a camera, smart phone, and computer during use, crude estimates could be determined by hand calculations of the same equations using a stopwatch and hand rotation counting to determine the RCF.

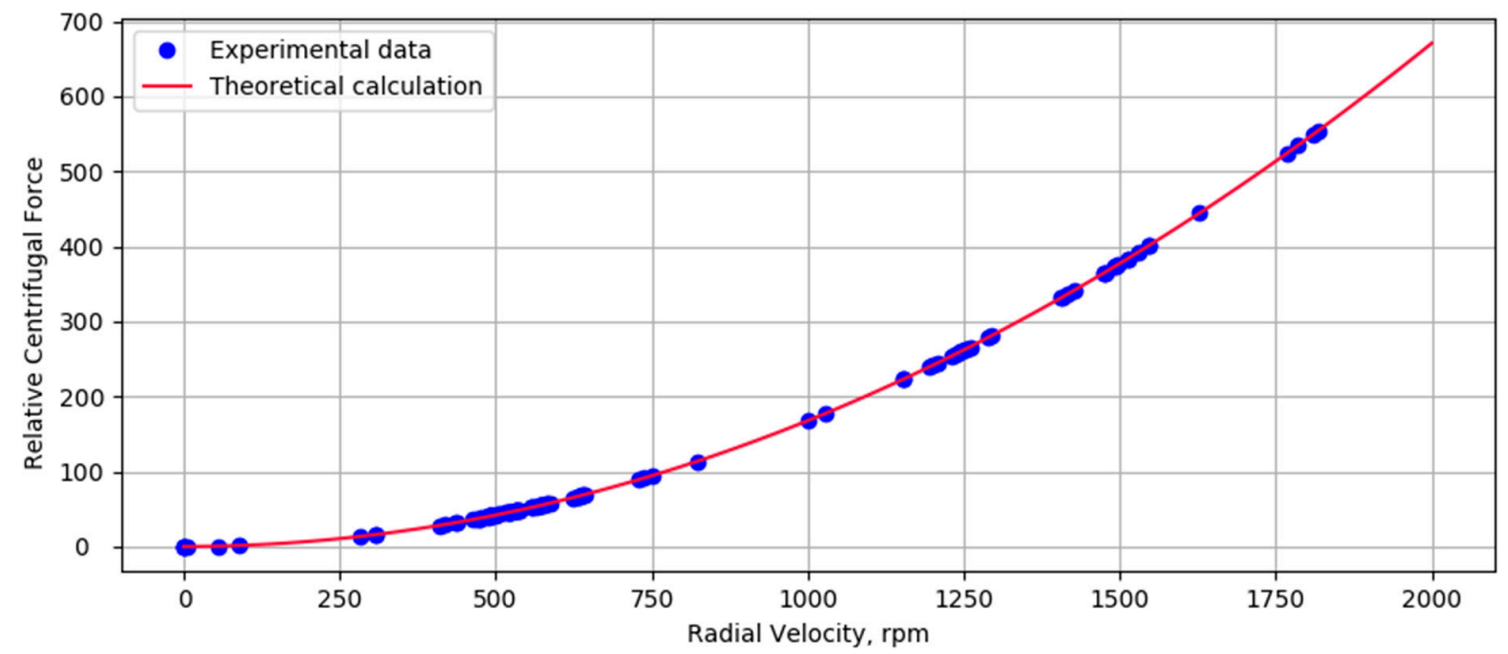

Figure 12. Relative centrifugal force as a function of the rotational velocity of the centrifuge test tubes with a length of $100 \mathrm{~mm}$ and a total radius of rotation $D=150 \mathrm{~mm}$ (Equation (7)).

\section{Discussion}

This study successfully described, tested, and validated a completely open source centrifuge, which can be fabricated using only open source tools, validated with a laptop computer with a webcam using only free and open source software, and operated anywhere in the world with no electricity inputs. In addition, this device can be fabricated for far less than commercial proprietary tools. The total mass of the apparatus is $0.550 \mathrm{~kg}$, which results in about U.S. $\$ 0.50$ in electricity costs and $\$ 24.75$ in commercial costs of filament, for a total cost of U.S. \$25.26. Parts $\mathrm{M}$ and $\mathrm{N}$ both require printing with support and the use of 2 and $11 \mathrm{~g}$, respectively. This adds about 60 U.S. cents to the total cost (U.S. \$25.88). This compares to commercial systems, which cost U.S. \$60-100 [59,60] and do not have a means of easy field validation without the use of the open source GUI disclosed here. Thus, a considerable savings of a $57-75 \%$ decrease in cost can be achieved with this device. However, as this device is primarily developed for applications in resource-constrained settings, further cost reductions are needed.

The economics of using commercial 3-D printing filament are somewhat attractive: However, they can be improved by using filament fabricated with a recyclebot [73-75] from recycled waste polymers. Former 3-D printed polymers can be recycled with acceptable mechanical strengths for about five cycles [76,77]. Thermopolymers, which have already been demonstrated with recyclebot processing, include polylactic acid (PLA) [75-79], PET and PETG [80-82], high-density polyethylene (HDPE) [74,82-87], acrylonitrile butadiene styrene (ABS) [82,86-90], polystyrene (PS) [82], polypropylene (PP) [82], elastomers [91], as well as polypropylene blends [92] and composites such as waste wood biopolymers [93] and carbon fiber-reinforced plastics [94]). Modern recyclebots can produce filament from waste plastic for electricity costs between 2.4 [90] and 3.6 [75] cents $/ \mathrm{kg}$. As the 
design here was massed at $0.550 \mathrm{~kg}$, it would cost between 1.3 and 2 cents in recycled filament and about 91 cents to print, which results in a total cost of about U.S. \$0.92-\$0.93. This provides savings of $98 \%-99 \%$ compared to commercial offerings. It should be pointed out here that these costs do not include any labor costs for either the collecting, sorting, or processing (shredding) of the waste plastic to feedstock for the recyclebot. Commercial recycled plastic granules are available from U.S. $\$ 1.00-3.00 / \mathrm{kg}$. Purchasing relatively expensive commercial recycled plastic would still result in a centrifuge cost of only a dollar or two. However, there are two ways these costs can be even further reduced from the sub-dollar costs associated with distributed recycling with a recyclebot system. The first involves using a previously acquired solar photovoltaic-powered recyclebot $[78,87,89]$ and a solar-powered 3-D printer $[87,89,95-97]$. The electricity costs are then avoided, dropping the marginal costs of materials and energy near to zero, although the capital cost would need to be amortized by printing many valuable products or be given as a donation. In addition, direct fused particle fabrication (FPF) or fused granular fabrication (FGF) can be used to recycle a wide range of materials, including PET, PP, ABS, and PLA [98]. Directly printing (material extrusion) shredded waste plastic and avoiding filament manufacturing takes the cost of the materials and processing of the open source centrifuge down under U.S. \$0.50. The commercial open source FPF/FGF systems have high capital costs, although they can fabricate generally large, valuable products that provide users with a high return on investment if they are used frequently [99]. Future work is needed to make a desktop scale particle material extrusion 3-D printer and apply it to manufacturing of this device.

This study indicates several areas of future work. First, more research is needed to make small-scale FPF/FGF 3-D printers to fabricate waste plastic into open source centrifuges for resource-constrained areas. Such systems would ideally be solar photovoltaic-powered. Future work could also look at the potential for a 3-D printable waste plastic shredder, again ideally solar or manual powered, that could be used to complete the entire tool chain from waste to finished scientific instrument. It should be noted that in the cost calculations above, labor costs were not included. Future work can address the labor costs in a range of contexts: However, a past analysis of open hardware for science by Trivedi et al. [23] has shown that zero labor costs are relevant to several scientific instrument situations where (i) there is no opportunity cost to using existing salaried employees (e.g., lab managers, research assistants, teaching assistants, or other positions that are paid as a fixed cost and for which there is no opportunity cost of work on the fabrication of the device); (ii) fabrication of the instruments is used as a learning aid [100,101]; or (iii) the labor is provided by unpaid interns or volunteers (e.g., undergraduate students volunteering for research experience). In general, in resource-constrained settings, as well as in most academic institutions, these conditions can be met. For those settings where this is not the case, tasks to order and deploy a commercial product should be compared to the relatively low time investment of printing (only set-up and take-off is necessary, as the 3-D printers can be left unattended) and assembling the open source centrifuge.

\section{Conclusions}

This paper provides complete open source plans, including a BOM, instructions for fabrication and operation, and open source software for a hand-powered centrifuge. This study successfully described, tested, and validated this completely open source centrifuge, which can be fabricated using only open source tools (e.g., a RepRap-class 3-D printer). Further, the validation itself used only open source and readily available tools of a computer with a webcam. The instrument can be operated anywhere in the world with no electricity inputs, obtaining a radial velocity of over $1750 \mathrm{rpm}$ and over $50 \mathrm{~N}$ of relative centrifugal force. Using commercial filament, the instrument costs about U.S. $\$ 25$, which is less than half of all commercially available systems. However, the costs can be dropped further using recycled plastics in open source systems for over $99 \%$ savings.

Supplementary Materials: The following are available online at http://www.mdpi.com/2410-390X/3/2/30/s1. Video S1: MOST_CENTRIFUGE_VIDEO.avi. 
Author Contributions: Conceptualization, J.M.P.; data curation, A.L.P.; formal analysis, S.S.S., A.L.P., and J.M.P.; funding acquisition, J.M.P.; investigation, S.S.S. and A.L.P.; methodology, S.S.S., A.L.P., and J.M.P.; resources, J.M.P.; software, A.L.P.; supervision, J.M.P.; validation, A.L.P.; visualization, S.S.S. and A.L.P.; writing-original draft, S.S.S., A.L.P., and J.M.P.; writing-review and editing, S.S.S., A.L.P., and J.M.P.

Funding: This research was funded by Aleph Objects and the Richard Witte Endowment.

Acknowledgments: The authors would like to thank Shaunak P. Mhatre for technical assistance.

Conflicts of Interest: The authors declare no conflict of interest. The funders had no role in the design of the study; in the collection, analyses, or interpretation of data; in the writing of the manuscript; or in the decision to publish the results.

\section{References}

1. Gibb, A. Building Open Source Hardware: DIY Manufacturing for Hackers and Makers; Pearson Education: New York, NY, USA, 2014.

2. Da Costa, E.T.; Mora, M.F.; Willis, P.A.; do Lago, C.L.; Jiao, H.; Garcia, C.D. Getting started with open-hardware: Development and control of microfluidic devices. Electrophoresis 2014, 35, 2370-2377. [CrossRef] [PubMed]

3. Ackerman, J.R. Toward open source hardware. U. Dayton L. Rev. 2008, 34, 183-222.

4. Powell, A. Democratizing production through open source knowledge: From open software to open hardware. Media Cult. Soc. 2012, 34, 691-708. [CrossRef]

5. Von Hippel, E. Democratizing innovation: The evolving phenomenon of user innovation. JfB 2005, 55, 63-78. [CrossRef]

6. Blikstein, P. Digital fabrication and "making" in education: The democratization of invention. FabLabs Mach. Mak. Invent. 2013, 4, 1-21.

7. Gershenfeld, N. How to Make Almost Anything: The Digital Fabrication Revolution. Available online: http://cba.mit.edu/docs/papers/12.09.FA.pdf (accessed on 16 May 2019).

8. Wittbrodt, B.; Laureto, J.; Tymrak, B.; Pearce, J. Distributed manufacturing with 3-d printing: A case study of recreational vehicle solar photovoltaic mounting systems. J. Frugal Innov. 2015, 1, 1-7. [CrossRef]

9. Sells, E.; Bailard, S.; Smith, Z.; Bowyer, A.; Olliver, V. RepRap: The Replicating Rapid Prototyper-Maximizing Customizability by Breeding the Means of Production. In Proceedings of the World Conference on Mass Customization and Personalization, Cambridge, MA, USA, 7-10 October 2007.

10. Jones, R.; Haufe, P.; Sells, E.; Iravani, P.; Olliver, V.; Palmer, C.; Bowyer, A. RepRap-the replicating rapid prototyper. Robotica 2011, 29, 177-191. [CrossRef]

11. Bowyer, A. 3D Printing and humanity's first imperfect replicator. 3D Print. Addit. Manuf. 2014, 1, 4-5. [CrossRef]

12. Kietzmann, J.; Pitt, L.; Berthon, P. Disruptions, decisions, and destinations: Enter the age of 3-D printing and additive manufacturing. Bus. Horiz. 2015, 58, 209-215. [CrossRef]

13. Lipson, H.; Kurman, M. Fabricated: The New World of 3D Printing; John Wiley \& Sons: Indianapolis, IN, USA, 2013.

14. Gwamuri, J.; Wittbrodt, B.; Anzalone, N.; Pearce, J. Reversing the trend of large scale and centralization in manufacturing: The case of distributed manufacturing of customizable 3-d-printable self-adjustable glasses. Chall. Sustain. 2014, 2, 30-40. [CrossRef]

15. Attaran, M. The rise of 3-D printing: The advantages of additive manufacturing over traditional manufacturing. Bus. Horiz. 2017, 60, 677-688. [CrossRef]

16. Tanikella, N.G.; Wittbrodt, B.; Pearce, J.M. Tensile strength of commercial polymer materials for fused filament fabrication 3D printing. Addit. Manuf. 2017, 15, 40-47. [CrossRef]

17. Pearce, J.M. Building research equipment with free, open-source hardware. Science 2012, 337, $1303-1304$. [CrossRef] [PubMed]

18. Pearce, J. Open-Source Lab: How to Build Your Own Hardware and Reduce Research Costs; Elsevier: New York, NY, USA, 2013.

19. Baden, T.; Chagas, A.M.; Gage, G.; Marzullo, T.; Prieto-Godino, L.L.; Euler, T. Open labware: 3-D printing your own lab equipment. PLoS Biol. 2015, 13, e1002086. [CrossRef] [PubMed]

20. Coakley, M.; Hurt, D.E. 3D Printing in the laboratory: Maximize time and funds with customized and open-source labware. J. Lab. Autom. 2016, 21, 489-495. [CrossRef] [PubMed] 
21. Zhang, C.; Wijnen, B.; Pearce, J.M. Open-Source 3-D platform for low-cost scientific instrument ecosystem. J. Lab. Autom. 2016, 21, 517-525. [CrossRef] [PubMed]

22. Dhankani, K.C.; Pearce, J.M. Open source laboratory sample rotator mixer and shaker. HardwareX 2017, 1, 1-12. [CrossRef]

23. Trivedi, D.K.; Pearce, J.M. Open Source 3-D Printed Nutating Mixer. Appl. Sci. 2017, 7, 942. [CrossRef]

24. Zhang, C.; Anzalone, N.C.; Faria, R.P.; Pearce, J.M. Open-Source 3D-Printable Optics Equipment. PLoS ONE 2013, 8, e59840. [CrossRef]

25. Winters, B.J.; Shepler, D. 3D printable optomechanical cage system with enclosure. HardwareX 2018, 3, $62-81$. [CrossRef]

26. Agcayazi, T.; Foster, M.; Kausche, H.; Gordon, M.; Bozkurt, A. Multi-axis stress sensor characterization and testing platform. HardwareX 2019, 5, e00048. [CrossRef]

27. Anzalone, G.C.; Glover, A.G.; Pearce, J.M. Open-Source Colorimeter. Sensors 2013, 13, 5338-5346. [CrossRef] [PubMed]

28. Kelley, C.D.; Krolick, A.; Brunner, L.; Burklund, A.; Kahn, D.; Ball, W.P.; Weber-Shirk, M. An Affordable Open-Source Turbidimeter. Sensors 2014, 14, 7142-7155. [CrossRef] [PubMed]

29. Wijnen, B.; Anzalone, G.C.; Pearce, J.M. Open-source mobile water quality testing platform. J. Water Sanit. Hyg. Dev. 2014, 4, 532-537. [CrossRef]

30. Wittbrodt, B.T.; Squires, D.A.; Walbeck, J.; Campbell, E.; Campbell, W.H.; Pearce, J.M. Open-Source Photometric System for Enzymatic Nitrate Quantification. PLoS ONE 2015, 10, e0134989. [CrossRef]

31. Wijnen, B.; Hunt, E.J.; Anzalone, G.C.; Pearce, J.M. Open-Source Syringe Pump Library. PLoS ONE 2014, 9, e107216. [CrossRef]

32. Bravo-Martinez, J. Open source 3D-printed $1000 \mu \mathrm{L}$ micropump. HardwareX 2018, 3, 110-116. [CrossRef]

33. Pusch, K.; Hinton, T.J.; Feinberg, A.W. Large volume syringe pump extruder for desktop 3D printers. HardwareX 2018, 3, 49-61. [CrossRef]

34. Garcia, V.E.; Liu, J.; DeRisi, J.L. Low-cost touchscreen driven programmable dual syringe pump for life science applications. HardwareX 2018, 4, e00027. [CrossRef]

35. Pearce, J.M.; Anzalone, N.C.; Heldt, C.L. Open-Source Wax RepRap 3-D Printer for Rapid Prototyping Paper-Based Microfluidics. J. Lab. Autom. 2016, 21, 510-516. [CrossRef]

36. Kong, D.S.; Thorsen, T.A.; Babb, J.; Wick, S.T.; Gam, J.J.; Weiss, R.; Carr, P.A. Open-source, community-driven microfluidics with Metafluidics. Nat. Biotechnol. 2017, 35, 523-529. [CrossRef] [PubMed]

37. Niezen, G.; Eslambolchilar, P.; Thimbleby, H. Open-source hardware for medical devices. BMJ Innov. 2016, 2, 78-83. [CrossRef] [PubMed]

38. Beeker, L.Y.; Pringle, A.M.; Pearce, J.M. Open-source parametric 3-D printed slot die system for thin film semiconductor processing. Addit. Manuf. 2018, 20, 90-100. [CrossRef]

39. Pearce, J.M. Laboratory equipment: Cut costs with open-source hardware. Nature 2014, 505, 618. [CrossRef] [PubMed]

40. Pearce, J.M. Impacts of Open Source Hardware in Science and Engineering. Bridge 2017, 47, $24-31$.

41. Hietanen, I.; Heikkinen, I.T.S.; Savin, H.; Pearce, J.M. Approaches to open source 3-D printable probe positioners and micromanipulators for probe stations. HardwareX 2018, 4, e00042. [CrossRef]

42. Pearce, J. Quantifying the Value of Open Source Hardware Development. Mod. Econ. 2015, 6, 1-11. [CrossRef]

43. Pearce, J.M. Return on investment for open source scientific hardware development. Sci. Public Policy 2016, 43, 192-195. [CrossRef]

44. Dryden, M.D.M.; Fobel, R.; Fobel, C.; Wheeler, A.R. Upon the Shoulders of Giants: Open-Source Hardware and Software in Analytical Chemistry. Anal. Chem. 2017, 89, 4330-4338. [CrossRef]

45. Cölfen, H.; Laue, T.M.; Wohlleben, W.; Schilling, K.; Karabudak, E.; Langhorst, B.W.; Brookes, E.; Dubbs, B.; Zollars, D.; Rocco, M.; et al. The Open AUC Project. Eur. Biophys. J. 2010, 39, 347-359. [CrossRef]

46. CopabX, OpenFuge. Available online: https://www.instructables.com/id/OpenFuge/ (accessed on $28 \mathrm{March}$ 2019).

47. Polyfuge: A DIY Open-Source Microcentrifuge for Everyone. Available online: https://www.kickstarter.com/ projects/1733191226/polyfuge-a-diy-open-source-microcentrifuge-for-eve (accessed on 28 March 2019).

48. Warejoncas, Z.; Stewart, C.; Giannini, J. An Inexpensive, Open-Source Mini-Centrifuge. AMBT 2018, 80, 451-456. [CrossRef] 
49. Progress TH Follow 3D Printed DIYbio Mini-Centrifuge. Available online: https://www.instructables.com/ id/3D-Printed-DIYbio-Mini-Centrifuge/ (accessed on 28 March 2019).

50. Thingiverse. El-Cheapo Table Top Mini Fuge by Tiny Tim. Available online: https://www.thingiverse.com/ thing:33818 (accessed on 28 March 2019).

51. Garvey, C. Thingiverse.com DremelFuge-A One-Piece Centrifuge for Rotary Tools by Cathal Garvey. Available online: https://www.thingiverse.com/thing:1483 (accessed on 28 March 2019).

52. Chagas, A.M. Haves and have nots must find a better way: The case for open scientific hardware. PLoS Biol. 2018, 16, e3000014.

53. International Energy Agency. Energy Access Outlook. Available online: https://www.iea.org/access2017/ (accessed on 28 March 2019).

54. Edomah, N. Governing sustainable industrial energy use: Energy transitions in Nigeria's manufacturing sector. J. Clean. Prod. 2019, 210, 620-629. [CrossRef]

55. Bhamla, M.S.; Benson, B.; Chai, C.; Katsikis, G.; Johri, A.; Prakash, M. Hand-powered ultralow-cost paper centrifuge. Nat. Biomed. Eng. 2017, 1, 0009. [CrossRef]

56. Brown, J.; Theis, L.; Kerr, L.; Zakhidova, N.; O'Connor, K.; Uthman, M.; Oden, Z.M.; Richards-Kortum, R. A hand-powered, portable, low-cost centrifuge for diagnosing anemia in low-resource settings. Am. J. Trop. Med. Hyg. 2011, 85, 327-332. [CrossRef] [PubMed]

57. Wong, A.P.; Gupta, M.; Shevkoplyas, S.S.; Whitesides, G.M. Egg beater as centrifuge: Isolating human blood plasma from whole blood in resource-poor settings. Lab. Chip. 2008, 8, 2032-2037. [CrossRef] [PubMed]

58. Hand-Driven Centrifuge. Southern Labware. Available online: https://www.southernlabware.com/handdriven-centrifuge.html (accessed on 28 March 2019).

59. Hand-Driven Centrifuge. Carolina.com. Available online: https://www.carolina.com/catalog/detail.jsp? prodId=701816\&s_cid=ppc_gl_products\&utm_source=google\&utm_medium=cpc\&scid=scplp701816\& Sc_intid=701816\&gclid=EAIaIQobChMIgIyF37yl4QIVwrfACh22aAlgEAQYAiABEgLe4PD_BwE (accessed on 28 March 2019).

60. Mabey, D.; Peeling, R.W.; Ustianowski, A.; Perkins, M.D. Tropical infectious diseases: Diagnostics for the developing world. Nat. Rev. Microbiol. 2004, 2, 231-240. [CrossRef]

61. Urdea, M.; Penny, L.A.; Olmsted, S.S.; Giovanni, M.Y.; Kaspar, P.; Shepherd, A.; Wilson, P.; Dahl, C.A.; Buchsbaum, S.; Moeller, G.; et al. Requirements for high impact diagnostics in the developing world. Nature 2006, 444, 73-79. [CrossRef]

62. Dineva, M.A.; Mahilum-Tapay, L.; Lee, H. Sample preparation: A challenge in the development of point-of-care nucleic acid-based assays for resource-limited settings. Analyst 2007, 132, 1193-1199. [CrossRef]

63. Mariella, R. Sample preparation: The weak link in microfluidics-based biodetection. Biomed. Microdev. 2008, 10, 777. [CrossRef]

64. OSF. Available online: https://osf.io/besmf/ (accessed on 16 April 2019).

65. GNU General Public License Version 3. Available online: https://www.gnu.org/licenses/gpl-3.0.en.html (accessed on 29 March 2019).

66. Joe, J. Fully Printable C-Clamp Licensed Under Creative Commons-Attribution License. Available online: https://www.thingiverse.com/thing:1673030 (accessed on 29 March 2019).

67. Cura LulzBot Edition. Available online: https://www.lulzbot.com/cura (accessed on 2 April 2019).

68. OpenCV (Open Source Computer Vision Library). Available online: https://opencv.org/ (accessed on 16 April 2019).

69. PyQt. Available online: https://wiki.python.org/moin/PyQt (accessed on 16 April 2019).

70. MOST_Centrifuge_GUI. Available online: https://github.com/apetsiuk/MOST_Centrifuge_GUI (accessed on 16 April 2019).

71. EIA. Electric Power Monthly. Available online: https://www.eia.gov/electricity/monthly/epm_table_grapher. php?t=epmt_5_6_a (accessed on 16 April 2019).

72. PETg 3D Printer Filament. IC3D Filament. Available online: https://www.lulzbot.com/store/filament/ic3dpetg (accessed on 2 April 2019).

73. Recyclebot. Appropedia. Available online: http://www.appropedia.org/Recyclebot (accessed on 2 April 2019).

74. Baechler, C.; DeVuono, M.; Pearce, J.M. Distributed recycling of waste polymer into RepRap feedstock. Rapid Prototyp. J. 2013, 19, 118-125. [CrossRef] 
75. Woern, A.L.; McCaslin, J.R.; Pringle, A.M.; Pearce, J.M. RepRapable Recyclebot: Open source 3-D printable extruder for converting plastic to 3-D printing filament. HardwareX 2018, 4, e0026. [CrossRef]

76. Cruz Sanchez, F.; Lanza, S.; Boudaoud, H.; Hoppe, S.; Camargo, M. Polymer recycling and additive manufacturing in an open source context: Optimization of processes and methods. In Proceedings of the 2015 Annual International Solid Freeform Fabrication Symposium-An Additive Manufacturing Conference, Austin, TX, USA, 12-14 August 2015; pp. 10-12.

77. Cruz Sanchez, F.A.C.; Boudaoud, H.; Hoppe, S.; Camargo, M. Polymer recycling in an open-source additive manufacturing context: Mechanical issues. Addit. Manuf. 2017, 17, 87-105. [CrossRef]

78. Zhong, S.; Rakhe, P.; Pearce, J.M. Energy Payback Time of a Solar Photovoltaic Powered Waste Plastic Recyclebot System. Recycling 2017, 2, 10. [CrossRef]

79. Anderson, I. Mechanical properties of specimens $3 \mathrm{~d}$ printed with virgin and recycled polylactic acid. $3 D$ Print. Addit. Manuf. 2017, 4, 110-115. [CrossRef]

80. Woern, A.L.; Pearce, J.M. 3-D Printable polymer pelletizer chopper for fused granular fabrication-based additive manufacturing. Inventions 2018, 3, 78. [CrossRef]

81. Zander, N.E.; Gillan, M.; Lambeth, R.H. Recycled polyethylene terephthalate as a new FFF feedstock material. Addit. Manuf. 2018, 21, 174-182. [CrossRef]

82. Pepi, M.; Zander, N.; Gillan, M. Towards Expeditionary Battlefield Manufacturing Using Recycled, Reclaimed, and Scrap Materials. JOM 2018, 70, 2359-2364. [CrossRef]

83. Chong, S.; Pan, G.-T.; Khalid, M.; Yang, T.C.-K.; Hung, S.-T.; Huang, C.-M. Physical Characterization and Pre-assessment of Recycled High-Density Polyethylene as 3D Printing Material. J. Polym. Environ. 2017, 25, 136-145. [CrossRef]

84. Kreiger, M.; Anzalone, G.C.; Mulder, M.L.; Glover, A.; Pearce, J.M. Distributed recycling of post-consumer plastic waste in rural areas. MRS Online Proc. 2013, 1492, 91-96. [CrossRef]

85. Kreiger, M.A.; Mulder, M.L.; Glover, A.G.; Pearce, J.M. Life cycle analysis of distributed recycling of post-consumer high density polyethylene for 3-D printing filament. J. Clean. Prod. 2014, 70, 90-96. [CrossRef]

86. Mohammed, M.I.; Mohan, M.; Das, A.; Johnson, M.D.; Badwal, P.S.; McLean, D.; Gibson, I. A low carbon footprint approach to the reconstitution of plastics into 3D-printer filament for enhanced waste reduction. KnE Eng. 2017, 2, 234-241. [CrossRef]

87. Mohammed, M.I.; Wilson, D.; Gomez-Kervin, E.; Rosson, L.; Long, J. EcoPrinting: Investigation of Solar Powered Plastic Recycling and Additive Manufacturing for Enhanced Waste Management and Sustainable Manufacturing. In Proceedings of the 2018 IEEE Conference on Technologies for Sustainability (SusTech), Long Beach, CA, USA, 9-12 November 2018; pp. 1-6.

88. Mohammed, M.I.; Das, A.; Gomez-Kervin, E.; Wilson, D.; Gibson, I. EcoPrinting: Investigating the use of 100\% recycled Acrylonitrile Butadiene Styrene (ABS) for Additive Manufacturing. Solid Freeform Fabrication 2017. In Proceedings of the 28th Annual International Solid Freeform Fabrication Symposium, Austin, TX, USA, 7-9 August 2017.

89. Mohammed, M.I.; Wilson, D.; Gomez-Kervin, E.; Vidler, C.; Rosson, L.; Long, J. The recycling of E-Waste ABS plastics by melt extrusion and 3D printing using solar powered devices as a transformative tool for humanitarian aid. In Proceedings of the 29th Annual International Solid Freeform Fabrication Symposium, Austin, TX, USA, 13-15 August 2018.

90. Zhong, S.; Pearce, J.M. Tightening the loop on the circular economy: Coupled distributed recycling and manufacturing with recyclebot and RepRap 3-D printing. Resour. Conserv. Recycl. 2018, 128, 48-58. [CrossRef]

91. Woern, A.L.; Pearce, J.M. Distributed Manufacturing of Flexible Products: Technical Feasibility and Economic Viability. Technologies 2017, 5, 71. [CrossRef]

92. Zander, N.E.; Gillan, M.; Burckhard, Z.; Gardea, F. Recycled polypropylene blends as novel 3D printing materials. Addit. Manuf. 2019, 25, 122-130. [CrossRef]

93. Pringle, A.M.; Rudnicki, M.; Pearce, J. Wood Furniture Waste-Based Recycled 3-D Printing Filament. For. Prod. J. 2018, 68, 86-95. [CrossRef]

94. Tian, X.; Liu, T.; Wang, Q.; Dilmurat, A.; Li, D.; Ziegmann, G. Recycling and remanufacturing of 3D printed continuous carbon fiber reinforced PLA composites. J. Clean. Prod. 2017, 142, 1609-1618. [CrossRef]

95. King, D.L.; Babasola, A.; Rozario, J.; Pearce, J.M. Mobile Open-Source Solar-Powered 3-D Printers for Distributed Manufacturing in Off-Grid Communities. Chall. Sustain. 2014, 2, 18-27. [CrossRef] 
96. Gwamuri, J.; Franco, D.; Khan, K.Y.; Gauchia, L.; Pearce, J.M. High-Efficiency Solar-Powered 3-D Printers for Sustainable Development. Machines 2016, 4, 3. [CrossRef]

97. Khan, K.Y.; Gauchia, L.; Pearce, J.M. Self-sufficiency of 3-D printers: Utilizing stand-alone solar photovoltaic power systems. Renew. Wind Water Solar 2018, 5, 5. [CrossRef]

98. Woern, A.L.; Byard, D.J.; Oakley, R.B.; Fiedler, M.J.; Snabes, S.L.; Pearce, J.M. Fused Particle Fabrication 3-D Printing: Recycled Materials' Optimization and Mechanical Properties. Materials 2018, 11, 1413. [CrossRef] [PubMed]

99. Byard, D.J.; Woern, A.L.; Oakley, R.B.; Fiedler, M.J.; Snabes, S.L.; Pearce, J.M. Green fab lab applications of large-area waste polymer-based additive manufacturing. Addit. Manuf. 2019, 27, 515-525. [CrossRef]

100. Schelly, C.; Anzalone, G.; Wijnen, B.; Pearce, J.M. Open-source 3-D printing technologies for education: Bringing additive manufacturing to the classroom. J. Vis. Lang. Comput. 2015, 28, 226-237. [CrossRef]

101. Bailey, M.; Grieco, J.; Speights, A.; Weiss, R.G. 3D printing in the classroom and laboratory. J. Comput. Sci. Coll. 2015, 31, 183-184.

(C) 2019 by the authors. Licensee MDPI, Basel, Switzerland. This article is an open access article distributed under the terms and conditions of the Creative Commons Attribution (CC BY) license (http://creativecommons.org/licenses/by/4.0/). 